\title{
ANQUILOSIS DE MOLARES TEMPORALES: REVISIÓN DE LA LITERATURA Y REPORTE DE UN CASO
}

\begin{abstract}
Liliana Marlen Osorio A
Odontóloga, U. Santo Tomás, Residente de I año de la Especialización en Odontopediatría, U. Santo Tomás

Autor responsable de la correspondencia: Liliana Marlen Osorio A.

Correo electrónico: liliana_odontopediatria@yahoo.com.ar

Presentación realizada en el Concurso de Posters en el XIV Congreso Internacional de Odontología Pediátrica, en Santa Marta, junio 4 de 2005.

RESUMEN

La anquilosis dental de dientes deciduos es una patología de gran importancia. Los estudios publicados muestran una alta prevalencia y múltiples complicaciones clínicas que pueden ser evitadas con un diagnóstico temprano. El análisis de la etiología y el tratamiento de esta alteración no muestran datos concluyentes debido a que se encuentran pocos estudios clínicos longitudinales. La anquilosis se presenta por una alteración en el ligamento periodontal que produce una fusión del diente al hueso alveolar, afecta la exfoliación de los dientes temporales y, algunas veces, la erupción de los sucesores permanentes. El objetivo de este artículo es hacer una revisión de la literatura y describir un caso de anquilosis bilateral de segundos molares inferiores deciduos y su tratamiento. [Osorio LM. Anquilosis de molares temporales: revisión de la literatura y reporte de un caso. Ustasalud Odontología 2005; 5: 122 - 127]
\end{abstract}

Palabras clave: Anquilosis dental, Infraoclusión, Dientes sumergidos.

\section{ANKYLOSIS OF PRIMARY MOLARS: A REVIEW AND REPORT OF A CASE}

\begin{abstract}
The ankylosis of primary molars is a pathology of great importance. The published studies show a high prevalence and many clinical complications that can early be avoided with an early diagnosis. The analysis of the causes and the treatment of this alteration do not show conclusive data because are few longitudinal clinical studies. The ankylosis appears by an alteration in the periodontal ligament that produces a fusion of the tooth to the alveolar bone, affects the exfoliation of the primary teeth and, some times, the eruption of the permanent successors. The objective of this paper is to make a literature review and to describe a case of bilateral ankylosis of second mandibular primary molars and their treatment.
\end{abstract}

Key words: Ankylosis, Infraocclusion, Submerged teeth.

Recibido para publicación: 23 de mayo de 2005. Aceptado para publicación: 2 de noviembre de 2005.

\section{INTRODUCCIÓN}

La anquilosis dento-alveolar se puede definir como una fusión anatómica del cemento o dentina con el hueso alveolar. Tal situación hace que el diente anquilosado permanezca bajo el plano oclusal de los dientes adyacentes. ${ }^{1-11}$ Esta patología puede ocurrir en cualquier etapa del periodo eruptivo (retención primaria) o cuando ya se ha establecido un contacto oclusal (retención secundaria) y es asintomática. ${ }^{3,5,7,8,12,13}$

Se han usado diferentes terminologías para describir este fenómeno: erupción detenida, depresión, impactación, erupción incompleta, intrusión, reimpactación, reinclusión, retención secundaria y diente sumergido. Los más acertados son anquilosis e infraoclusión ya que los dien- 
tes anquilosados están en un estado de retención estática mientras que las zonas adyacentes continúan con su proceso normal eruptivo y de crecimiento mandibular. ${ }^{1,5-}$ 7,10,14 También se le ha llamado "movimiento paradójico" al movimiento del diente hacia apical. ${ }^{12}$

Los molares temporales inferiores son los dientes que más frecuentemente presentan anquilosis. ${ }^{3-6,14-16}$ En algunos estudios epidemiológicos, se reporta una prevalencia que oscila desde $1.3 \%$ a $44 \%$. Los estudios no reportan diferencias entre sexos. ${ }^{3,68,9,13}$ Tampoco se reporta predilección por hemiarco. ${ }^{3}$ La patología usualmente ocurre en la etapa de dentición mixta temprana (6-11años). 1,5,8

\section{Etiología}

La etiología exacta de la anquilosis es desconocida. ${ }^{2,3,6,16,17}$ Es un fenómeno extraño que involucra alteraciones en el proceso fisiológico de erupción. ${ }^{16}$ Sin embargo, se han propuesto tres causas probables:

1. Falla genética o congénita del ligamento periodontal.

2. Presión masticatoria excesiva o trauma.

3. Alteración metabólica de carácter local o sistémico, lo que hace que el ligamento periodontal desaparezca en algunas zonas. ${ }^{6,9,10,13,18}$

La anquilosis es la causa más común de la erupción dental retardada de dientes permanentes y podría ser la manifestación única o principal de una patología local o sistémica. ${ }^{18}$

El hipotiroidismo, hipopituitarismo, hipoparatidoidismo y seudoparatiroidismo son los trastornos endocrinos mas comúnmente relacionados con esta patología. También se ha reportado en pacientes con deficiencia de algún nutriente esencial, principalmente por deficiencia de vitamina D. Otras afecciones sistémicas relacionadas son la anemia, falla renal, intoxicación por metales y desordenes genéticos. ${ }^{18}$

Se ha demostrado que medicamentos como la fenitoina y algunos utilizados en la quimioterapia afectan la erupción normal de los dientes temporales y permanentes. Así como también se ha observado la alta incidencia de anquilosis dental en ratones irradiados con rayos X. ${ }^{18}$

Actualmente, el conocimiento de la biología de la erupción del diente así como los mecanismos moleculares básicos implicados en los problemas eruptivos, son nece- sarios para el clínico que se enfrenta con este tipo de patología dental. Dentro de los principales genes reguladores y factores de trascripción que pueden estar alterados en este proceso eruptivo, conocidos hasta el momento, se encuentran: Factor de crecimiento epidermal EGF, Factor de crecimiento transformante alfa TGF alfa, Factores de trascripción del gen CFOX o Factor de trascripción de genes NFKB1 y NFKB2, Factor de diferenciación osteoclastica ODF, Receptor funcional tipo 1 para la Interleuquina 1 alfa IL-1R, Factor de trascripción osteoblástico específico Cbfa1 (Runx2) y Factor estimulante de colonias uno CSF-1. ${ }^{11}$

Adicionalmente, las fallas en el proceso de erupción no solamente tienen distintas etiologías genéticas sino que, también, resultan en ciertos diferentes fenotipos de erupción. ${ }^{11}$ Se puede apreciar que los procesos de erupción dental pueden ser alterados en diferentes etapas y pueden variar en severidad. ${ }^{11}$

Por lo tanto, una vez se diagnostica la infraoclusión, es de gran importancia investigar más a fondo la salud general y el desarrollo del paciente ya que podría ser un signo de una afección sistémica o genética. ${ }^{11,18}$

\section{Histología}

El proceso de reabsorción no es continuo sino interrumpido por periodos de inactividad. A un periodo de reabsorción le sigue un periodo de reparación. Esta reabsorción y reparación intermitente puede explicar los diversos grados de firmeza de los dientes temporales antes de su exfoliacion., ${ }^{3,14}$ En el curso de la fase reparadora, a menudo, se desarrolla una unión sólida entre el hueso y el diente temporal. Algunos autores afirman que este hecho determina las fallas o modificaciones en el diagnóstico clínico en las diferentes épocas. ${ }^{8,9}$

La anquilosis del molar temporal, generalmente, no ocurre hasta que comienza la reabsorción de su raíz. El cuadro histológico de la anquilosis es de hiperactividad. ${ }^{6}$ En los cortes histológicos se observa la presencia de lagunas de reabsorción en la región de la furca y en la superficie interna radicular. ${ }^{6}$ La reabsorción ocurre en una zona de vascularización aumentada.,14

\section{Diagnóstico}

El diagnóstico precoz de los cuadros de anquilosis dentoalveolar es muy importante frente a los problemas futu- 
ros que puede ocasionar. Clínicamente, es fácil de realizar por tratarse de un diente por debajo del plano de oclusión normal sin causa específica. ${ }^{3,4,6,8,9}$

También, puede hacerse comprobando la ausencia de movilidad del molar temporal en infraoclusión. ${ }^{3,6}$ Los dientes anquilosados no se mueven aún en casos de reabsorción radicular avanzada, esto constituye un signo patognomónico., ${ }^{3,9}$

La anquilosis puede confirmarse golpeando suavemente con un instrumento romo el diente sospechoso y los dientes normales adyacentes, para comparar los sonidos producidos. Los dientes anquilosados tendrán un sonido firme 0 sólido mientras que los dientes normales tendrán un sonido amortiguado por el ligamento periodontal intacto. ${ }^{2,4,6,14}$ Esta técnica de percusión puede fallar debido a su variabilidad y subjetividad, ya que depende de la habilidad del clínico para diferenciar los sonidos; adicionalmente, algunos dientes tienen pequeñas áreas de anquilosis y no presentan esta característica sonora. ${ }^{4,6,9}$

Radiográficamente, se pueden observar algunas áreas de discontinuidad de la membrana periodontal y otras áreas de apariencia intacta. Sin embargo, existen tipos de anquilosis que no son detectados en la radiografía. ${ }^{2,9}$ El examen radiológico es valioso para observar el nivel óseo marginal, reabsorción radicular del molar anquilosado, posición del sucesor permanente y su estadio de formación radicular. ${ }^{2,6}$

Todo lo anterior permite clasificar la anquilosis según el grado de severidad, en:

1. Leve, cuando la superficie oclusal está a $1 \mathrm{~mm}$ del plano oclusal.

2. Moderada, cuando la superficie oclusal está en el punto de contacto de los dientes adyacentes.

3. Severa, cuando la superficie oclusal esta en el nivel o debajo del nivel gingival de los dientes vecinos. ${ }^{3,6,9}$

La infraoclusión se mide desde el plano oclusal de los dientes adyacentes utilizando una regla metálica y calibradores. ${ }^{2}$

\section{Consecuencias clínicas}

Se relacionan directamente con el grado de severidad del caso. ${ }^{3}$ La infraoclusión de los molares temporales afecta el desarrollo óseo porque se detiene su crecimiento al mismo tiempo que se detiene la erupción del diente temporal.,

Algunos autores reportan que la no extracción de los molares deciduos en infraoclusión severa puede ocasionar una reducción del soporte alveolar para los premolares y una disminución del perímetro de arco por la mesialización del diente adyacente, causando así una degeneración progresiva de la oclusión. ${ }^{3-5,9,10,13,15}$

También, puede presentarse exfoliación tardía, extrusión del diente antagonista o mordida abierta lateral por interposición lingual. Además, un diente anquilosado puede aumentar la susceptibilidad a la caries, enfermedad periodontal e infecciones. ${ }^{9,10,13}$

Otras secuelas relacionadas con el sucesor permanente son: impactación o rotación del germen, trayectoria anormal de erupción, alteraciones en la formación radicular y atraso en la erupción. .,6,8 $^{-6}$

\section{Tratamiento}

Para el tratamiento de un diente anquilosado es muy importante el reconocimiento y el diagnóstico temprano para que se puedan utilizar las medidas terapéuticas indicadas en cada caso en particular., ${ }^{4,9}$ Depende de la edad del paciente, del grado de severidad de la infraoclusión, del compromiso de la oclusión, de la presencia y la localización del sucesor permanente. $2,4,6,9$

El tratamiento puede contemplar la exodoncia y la colocación de un mantenedor de espacio; sin embargo, a menos que haya problemas de caries o de pérdida de perímetro de arco, se debe optar por mantener el diente en observación. Es mejor un seguimiento clínico y radiográfico del caso cuando la cooperación del paciente es buena y se pueden realizar controles en periodos regulares. ${ }^{1,2,4,5,9,14,16} \mathrm{Si}$ el antagonista está extruido, se debe reconstruir la corona clínica para recuperar la dimensión vertical y conservar la oclusión normal. ${ }^{2,45,9}$

La mayoría de los dientes anquilosados exfolian naturalmente, a menudo con una demora promedio de seis meses, por lo tanto no deben ser extraídos, innecesariamente. ${ }^{14,8,16}$

La extracción está indicada cuando existe infraoclusión severa con pérdida de espacio que puede causar giroversión de los premolares, cuando existe migración severa 
de los dientes adyacentes; cuando puede haber erupción ectópica del sucesor permanente o cuando hay formación de abscesos o grandes caries asociadas al diente anquilosado. ${ }^{5,89}$ Otros autores recomiendan la luxación del diente anquilosado como un medio para estimular la erupción. ${ }^{4,9}$

Aunque existen algunas reglas generales, en la mayoría de los casos, el tratamiento de la anquilosis debe ser evaluado según las condiciones particulares de cada paciente. ${ }^{2,4,9}$

A medida que avanzan los estudios de investigación se puede vislumbrar que las modalidades de tratamiento futuro pueden incluir terapéuticas que recrean los eventos de erupción. Es importante, para el éxito de estos tratamientos, que las herramientas de diagnóstico puedan diferenciar entre varios tipos de alteraciones en la erupción dental y, finalmente, apuntar hacia un régimen apropiado de tratamiento. ${ }^{11}$

Tal conocimiento no solamente, brinda un mejor entendimiento del proceso de erupción dental, sino que, también, conlleva al desarrollo de intervenciones terapéuticas eficaces para estos problemas de erupción que son retos clínicos. Cuando los procedimientos de biología molecular estén disponibles para entregar las moléculas apropiadas o los factores necesarios para la erupción individual de los dientes, el clínico podrá seleccionar el tratamiento adecuado para el paciente basado en la causa específica del problema de erupción. ${ }^{11}$

\section{REPORTE DE UN CASO}

Paciente de género femenino con diez años de edad. Asistió a las clínicas odontológicas de la Universidad Santo Tomás en Floridablanca para un examen general. Sin antecedentes médicos de importancia, apariencia física y desarrollo psicomotor normal. Dentro de los antecedentes médicos familiares se encontró que la abuela materna presentaba hipotiroidismo.

Clínicamente, se observó: respiración oral, relación molar clase II de Angle, sobremordida vertical del 60\%, sobremordida horizontal de $4 \mathrm{~mm}$, sin caries y con buena higiene oral. Dentro de los antecedentes dentales se encontró pérdida prematura de caninos y primeros molares inferiores temporales sin la erupcion de los sucedáneos permanentes.
También, se observó infraoclusión a nivel del segundo molar temporal inferior derecho e izquierdo (Figura $1 \mathrm{y}$ 2). La paciente no reportó sintomatología alguna relacionada con esta patología ni antecedente de trauma dental.

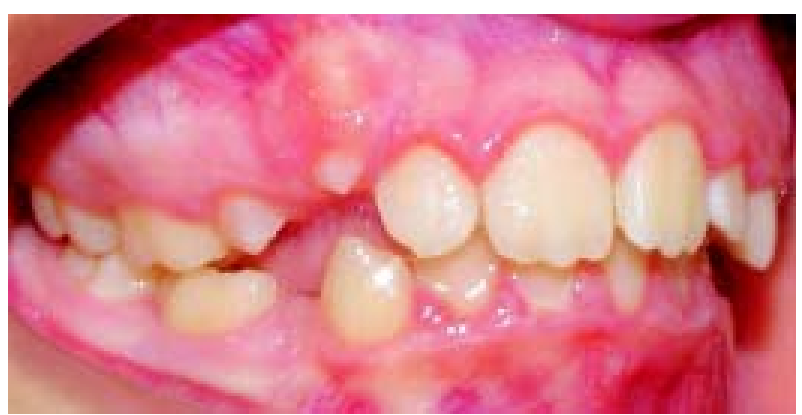

Figura 1. Oclusión lateral derecha.

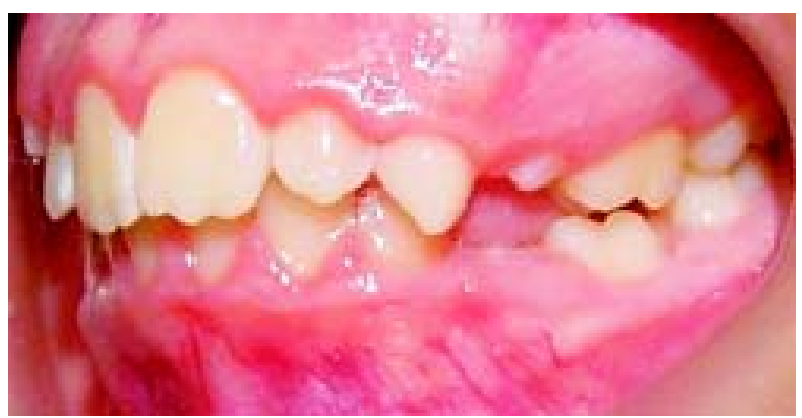

Figura 2. Oclusión lateral izquierda.

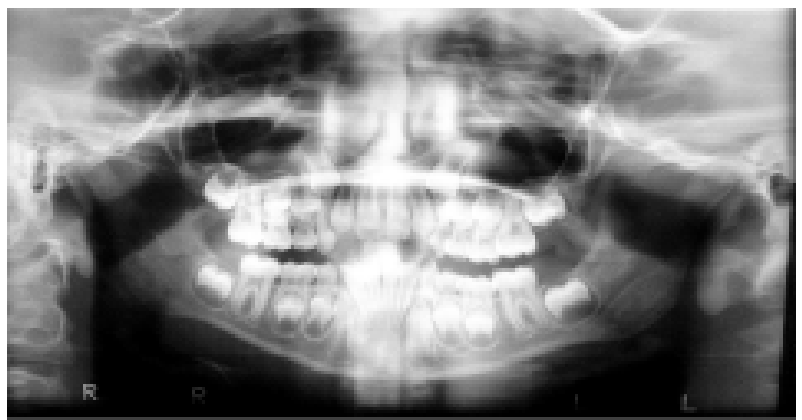

Figura 3. Radiografía panorámica previa.

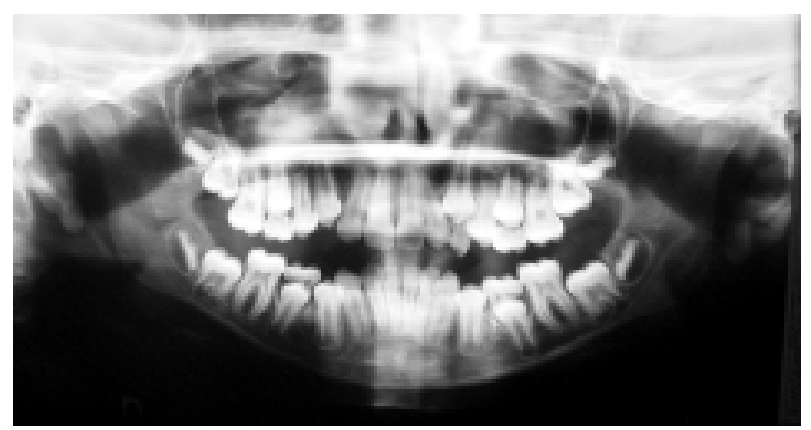

Figura 4. Radiografía panorámica actual. 
Se realizó la percusión en estos molares (75 y 85), y en los dientes adyacentes. En los dientes con infraoclusión el sonido fue claro y firme, mientras que en los otros fue más difuso. Este hecho es compatible con anquilosis dental. Además, estos molares deciduos presentaban ausencia de movilidad.

Radiográficamente, se observó infraoclusión de los segundos molares deciduos inferiores aunque su reabsorción radicular era normal, ausencia de lesiones periapicales relacionadas con la patología, sucesor permanente en cada hemiarco en posición adecuada para su erupción y en estadio 8 de Nolla 19 (Figura 3, 4).

Se tomaron modelos en los que se pudo medir el grado de infraoclusión y en los que se realizó el análisis de dentición mixta de Moyers. El segundo molar inferior derecho se encontró con una infraoclusión moderada y el segundo molar inferior izquierdo, con una infraoclusión severa.

Posteriormente, los padres de la paciente entregaron los modelos (superior e inferior) y una radiografía panorámica que habían sido tomados a la paciente dos años antes (Figura 3).

Estas ayudas diagnósticas sirvieron para comprobar que la patología ya se estaba presentando en esa época pero en menor escala, siendo más pronunciada en el segundo molar inferior izquierdo temporal, acompañada de una mesialización leve del primer molar inferior izquierdo permanente, posición que no empeoro con el desarrollo de la erupción.

Debido a la gran relación que tiene la infraoclusión con entidades sistémicas de origen endocrino y nutricional, se remitió a la paciente con el médico general. Se encontró que la paciente estaba muy baja en talla y peso para su edad; a su vez se remitió con el endocrino para valoración. Se le practicaron pruebas de laboratorio que incluyeron cuadro hemático, T4, TSH y estradiol. Los resultados de las pruebas clínicas reportaron normalidad.

Para el tratamiento se evaluó la edad de la paciente, los molares antagonistas sin extrusión, la ausencia de patologías asociadas con los molares anquilosados, la secuencia de erupción, la reabsorción radicular avanzada, los sucesores permanentes en posición normal para la erupción, con estadio 8 de Nolla y la posibilidad de realizar seguimiento. Se optó por realizar controles periódicos hasta la exfoliacion natural de los deciduos en infraoclu- sión. Actualmente, la paciente se encuentra en tratamiento de ortodoncia interceptiva para corregir la maloclusión y en asesoria con una nutricionista para corregir sus hábitos alimenticios y suplir las deficiencias nutricionales.

\section{DISCUSIÓN}

No existe un acuerdo general referente al tratamiento de la anquilosis de los molares temporales, debido a que la mayoría de los hallazgos citados se basan en reportes de casos y son pocos los estudios longitudinales sobre el efecto de los tratamientos. ${ }^{1}$

Algunos autores indican que no realizar a tiempo las extracciones de molares en severa infraoclusión da por resultado la reducción del soporte de hueso alveolar para los premolares. ${ }^{4,9,15}$

Otros autores recomiendan el seguimiento estricto de estos dientes ya que la mayoría exfolian naturalmente y su extracción, sólo, se aconseja cuando está claramente indicada ya que la remoción del diente puede ocasionar la fractura de las raíces o en el caso de los molares superiores anquilosados, puede ocurrir una comunicación oro-antral.

Asi mismo, los mantenedores de espacio pueden aumentar el riesgo de caries o enfermedad periodontal. 1,2,4,8

La gran discrepancia encontrada en la prevalencia se debe, posiblemente, a los diferentes criterios diagnósticos y a la diferencia de edad entre los niños estudiados. ${ }^{6,13}$ Los autores concuerdan en afirmar que no existe diferencia entre sexos y que se presenta más en niños de raza blanca que en niños de raza negra. ${ }^{6,13}$

Además, hay controversia en relación con los dientes temporales que más la presentan. Algunos autores reportan que el primer molar inferior es el más afectado, mientras que otros reportan que es el segundo molar inferior. ${ }^{5,6,13}$

En este artículo se presentó un caso de anquilosis bilateral de segundos molares temporales inferiores. El diagnóstico se realizó por observación clínica de la infra oclusión, pruebas de percusión, movilidad dental y examen radiográfico. Además, se contó con algunas ayudas diagnósticas que habían sido tomadas dos años atrás. A la paciente también se le realizaron pruebas de laboratorio para descartar alguna patología sistémica relacionada con la infraoclusión, resultando éstas normales. 
Se optó por no realizar la exodoncia de los dientes anquilosados y realizar seguimiento, considerando la edad de la paciente, la ausencia de caries o enfermedad periodontal asociada a los dientes anquilosados, la ausencia de extrusión de los dientes antagonistas, la secuencia de erupción, la reabsorción radicular normal y el estadio de Nolla de los sucesores.

\section{CONCLUSIONES}

1. No existen datos concluyentes sobre la etiología de esta patología, pero se conoce que se presenta por alteraciones en el ligamento periodontal.

2. La infraoclusión podría ser una manifestación de una patología local y sistémica, por lo que el clínico debe investigar más a fondo la salud y el desarrollo del paciente.

3. El tratamiento de los dientes anquilosados varía según el caso y se debe tener en cuenta la edad del paciente, el grado de infraoclusión, las alteraciones de la oclusión y el estado del sucesor permanente.

4. Es recomendable un monitoreo regular que debe cambiarse ante el primer signo de secuela indeseable.

5. Aún es prematuro obtener datos concluyentes sobre esta patología ya que faltan estudios longitudinales que permitan medir la progresión y los efectos oclusales de la infraoclusión de los molares temporales; así como las indicaciones, contraindicaciones y posibles secuelas de los diferentes métodos de tratamiento.

6. Los estudios en biología molecular investigan el desarrollo de una nueva terapéutica que pueda inducir a que los dientes impactados entren en erupción de una manera adecuada.

\section{BIBLIOGRAFÍA}

1. Kurol J, Koch G. The effect of extraction of infraoccluded deciduous molars: A longitudinal study. Am J Orthod Dentof Orthop 1985; 87 : 46 $-54$.

2. Kurol J, Thilander B. Infraocclusion of primary molars with aplasia of the permanent successor. A longitudinal study. Angle Orthod 1984; 54 : 283 - 294.

3. Crusoe-Rebello IMR, Araujo T, Lisboa J. Anquilose em dentes deciduos. J Bras Odontopediatr Odontol Bebe 2001; 4 : 501 - 505.
4. Delgado C, Moraes R. Anquilose Dento-Alveolar: Consederacoes sobre etilogia, diagnostico e posibilidades de tratamento. J Bras Odontopediatr Odontol Bebe 1999; 2: 167 - 174.

5. Ertugrul F, Tuncer A, Sezer B. Infraclusion of primary molars: A review and report of a case. J Dent Child 2002; 69: 166 - 171.

6. Castillos H, Konig J, Florián P. Aspectos clinicos e histologicos da anquilose multipla de molares deciduos: Relato de caso. J Bras Odontopediatr Odontol Bebe 2003; 6: 383 - 388.

7. De La Rosa Gay C, Valmaseda E, Costa X, Gay C. Infraclusion of primary molars: reports of cases. J Dent Child 1998; 65: 47 - 51.

8. Jones J, Robinson P. Submerging deciduous molars: An extraction in time. Dent Update 2001; 28: 309 - 311.

9. Albernaz C, Albernanz A. Anquilosis dental en molars deciduos: Relato de un caso. Rev. Fola/Oral 2000; 6: 83 - 87.

10. Kocadereli I, Turgut M. Management of oclusal and developmental disturbances resulting from an ankylosed maxillary second primary molar: Case report. J Dent Child 2003; 70: 178 -181.

11. Wise, G. Frazier-Bowers, S. D'Souza, R. Cellular, molecular and genetic determinants of tooth eruption. Crit Rev Oral Biol Med. 2004; 13: 323 - 334.

12. Pytlik W. Primary failure of eruption: A case report. Int Dent J 1991; 41: 274 - 278.

13. Altay N, Cengiz S. Space - regaining, treatment for a submerged primary molar: A case report. Int J Paediatr Dent 2002; 12: 286 - 289.

14. McDonald R, Avery D. Dentistry for the Child and Adolescent. 6ta. Edition. Ed. Mosby; 1994.

15. Kennedy D. Orthodontic management of missing teeth. J Can Dent Assoc 1999; 65: 548 - 550.

16. Antoniades K, Kavadia S, Milioti K, Antoniades V, Markovitsi E. Submerged teeth. J Clin Pediatr Dent 2002; 26: 239 - 242.

17. Zapata OA, Giraldo MP. Anquilosis dentaria. Revisión Bibliográfica. Rev Fac Odont Univ Ant 1995; 6: 57 -60.

18. Suri, L. Gagari, E. Delayed tooth eruption: Pathogenesis, diagnosis, and treatment. A literature review. Am J Orthod Dentof Orthop 2004; 126: 432 - 445.

19. Nolla C. Development of the permanent teeth. J Dent Child 1960; 27: 255-263. 